\title{
A educaÇao dos sentidos na leitura do Almanach- Album de São Carlos de 1916-1917
}

\author{
J osé Evaldo de Mello Doin* \\ jedoin@netside.com.br \\ Arrovani Luiz Fonseca ** \\ Humberto Perinelli Neto *** \\ perinellineto@yahoo.com.br \\ Rafael Cardoso de Mello **** \\ profrcmello@yahoo.com.br
}

Resumo: O objeto, o almanaque, é multifário em usos e atribuições e é tomado aqui como meio de traduzir e educar os indivíduos na modernidade local. Esse texto tem por finalidade explorar o universo da leitura fotográfica presente no ALMANACH-ALBUM DE 1916 - 1917 DE São CARLOS no que diz respeito a "educação dos sentidos", colocando o leitor em contato com os ditames do mundo do progresso da belle epoque cafeeira.

Palavras-Chave: almanaque, modernidade, educação sentidos, belle epoque

A educação dos sentidos na sociedade moderna e capitalista é fruto da multiplicação dos choques de experiência da modernidade. Nos dizeres de Marshall Berman, essa experiência, que forjou um novo homem e novos sentidos de relação com o mundo, provocou a sua soberania e o seu desterro.

Existe um tipo de experiência vital - experiência de tempo e espaço, de si mesmo e dos outros, das possibilidades e perigos da vida - que é

\footnotetext{
* Professor da UNESP/Franca/SP.

In Memorian - Ao mestre, amigo, professor, José Evaldo que se registre nosso carinho, admiração, estima dos seus alunos e orientandos que, agora, convivem com sua ausência preenchida de saudades e de boas lembranças das nossas intermináveis conversas. Somos frutos seus e semearemos muito mais, tenhamos certeza disso.

${ }_{* *}$ Doutorando da UNESP/Franca/SP.

$* * *$ Mestrando da UNESP/Franca/SP.

${ }^{* * * *}$ Mestrando da UNESP/Franca/SP.
} 
compartilhada por homens e mulheres em todo o mundo, hoje. Designarei esse conjunto de experiências como "modernidade". Ser moderno é encontrar-se em um ambiente que promete aventura, poder, alegria, crescimento, autotransformação e transformação das coisas em redor - mas, ao mesmo tempo, ameaça destruir tudo o que temos, tudo o que sabemos, tudo o que somos. A experiência ambiental da modernidade anula todas as fronteiras geográficas e raciais, de classe e nacionalidade, de religião e de ideologia: nesse sentido, pode-se dizer que a modernidade une a espécie humana. Porém, é uma unidade paradoxal, uma unidade de desunidade: ela nos despeja a todos num turbilhão de permanente desintegração e mudança, de luta e contradição, de ambigüidade e angústia. Ser moderno é fazer parte de um universo no qual, como disse Marx, "tudo o que é sólido desmancha no ar [Berman, p15].

Ainda pensando com Berman, este descreve as muitas formas de desenvolvimento da modernidade e seus horizontes humanos, técnicos e materiais:

O turbilhão da vida moderna tem sido alimentado por muitas fontes: grandes descobertas nas ciências físicas, com a mudança da nossa imagem do universo e do lugar que ocupamos nele; a industrialização da produção, que transforma conhecimento científico em tecnologia, cria novos ambientes humanos e destrói os antigos, acelera o próprio ritmo de vida, gera novas formas de poder corporativo e de luta de classes; descomunal explosão demográfica, que penaliza milhões de pessoas arrancadas de seu habitat ancestral, empurrando-as pelos caminhos do mundo em direção a novas vidas; rápido e muitas vezes catastrófico crescimento urbano; sistemas de comunicação de massa, dinâmicos em seu desenvolvimento, que embrulham e amarram, no mesmo pacote, os mais variados indivíduos e sociedades [Berman, p16].

No mais longínquo terreno periférico, houve a presença de ícones de progresso que procuraram moldar a vida urbana nos valores correspondentes à modernidade ao surgimento da necessidade de informação, e sociedade de consumo dos novos tempos das certezas. Nesses termos, estão os almanaques que principiam como publicação marcadamente construída dentro de uma identidade local.

Nesse sentido, buscarei neste texto mostrar como o almanaque, particularmente mostra-se como leitura de acesso reveladora de aspectos da modernidade. 
Usamos uma metáfora que nos conduziria por esse caminho. Uma viagem. Partilhando dessa palavra prenhe de sentidos, tomo emprestado de Rouanet, para que possamos articular melhor os caminhos que percorre, pelo menos em alguns aspectos, o ALMANACH-ALBUM DE SÃo CARLOS 1916 - 1917.

Rouanet fala de "viagem", ao propor que a condução de tal fato seja feita pelo flaneur de Baudelaire, que também foi condutor das análises de Benjamim. Proponho aqui uma viagem por páginas de uma publicação que, entre os muitos repertórios temáticos, pode funcionar como meio para atingir a sociedade de consumo, o almanaque. [Cf. ROUANET, 1993]

Peter Burke mostra a necessidade de observar a cidade como local de recepção não somente do seu próprio ambiente, mas também como receptadora das informações exteriores. De uma tradição oral no cotidiano das cidades verifica-se a passagem para uma comunicação escrita certamente fruto de uma sociedade sofrendo o impacto das transformações econômicas. Esse aspecto, lembra Burke, define a necessidade de um livro-guia, um ciceroni diante de uma cidade aberta e sem referências.

No século XVIII, esses livros-guia passaram a acrescentar à descrição das igrejas e das obras de arte algumas informações praticas, do tipo como negociar com os condutores de cabrioles ou quais ruas deviam ser evitadas a noite. Essa informação desatualizava-se rapidamente, de modo que não chega a ser surpresa constatar que, a partir de 1722, um guia de Madri para estrangeiros começasse a ser publicado anualmente. [BURKE, 1998. p. 198]

Assim, uma cidade mercadoria vai se formando com a necessidade de sua divulgação, pois esta é resultante também da sua consagração como fenômeno do capital. Mais que isso e em especial, os almanaques são a fonte desse turno de espaço e tempo. Nas páginas destes, a impressão de uma recriação da história encontra consentaneamente sua relação com o tempo presente, com as notícias presentes, e as gentes de influência do mundo político. Ele ainda reúne aspectos estatísticos das diversas profissões, monumentos históricos, festas, homenagens a expressividades locais, calendário, produção literária e anúncios sobre fábricas e casas comerciais. O almanaque, assim, "vende" a cidade, divulga, exalta, consagra. Sua leitura de fácil manuseio contém a "essência" local, colabora para o espírito de conquistas e situa o momento presente em suas novidades.

Situada no tema da urbanização essa contagem de dados que se faz dos almanaques pode se transformar na obtenção da imagem da cidade por 
meio desses fragmentos inscritos na leitura do texto. Uma leitura em que os detalhes levam ao renascimento de lugares, nomes, ofícios, cacos do espaço. Podemos assim pensar os almanaques, ao explicitar Ricardo Cordeiro Gomes, como um livro de registros [que] "faz o assentamento escritural da cidade, de que se quer conservar a lembrança; autentica-a, legitima-a, e preserva-lhe a identidade. Registrar [...] é levar para trás, transcrever, consignar; e, ainda reter na memória dessa cidade. O funcionário, o escriba [scriptor] que a inscreveu nesse livro, preserva-a do esquecimento o que possibilita o seu resgate, enquanto texto". [GOMES, 1989. p.37]

Retomando o sentido da viagem, algumas considerações devem ser feitas antes da partida. O ALMANACH-ALbUM DE São CARLOS 1916 - 1917 é uma publicação muito interessante e bem diferente das publicações anteriores da mesma cidade. Por se intitular duplamente como almanaque e álbum, privilegia aspectos textuais e fotográficos. Nessa combinação, o que nos chama a atenção é o misto desses dois elementos que dentro dos quadros da propaganda sugere uma educação do olhar leitor, ao mesmo tempo que se percebe um olhar do leitor imagético, que realça o discurso.

Cabe salientar a importância desse aspecto fotográfico. Para Kossoy, o fotógrafo que captura uma dada imagem fá-lo com vistas em um estado de espírito e uma ideologia, particularizando uma visão pessoal imbuída de certa bagagem cultural.

Toda fotografia representa em seu conteúdo uma interrupção do tempo e, portanto, da vida. O fragmento selecionado do real, a partir do instante em que foi registrado, permanecerá para sempre interrompido e isolado na bidimensão da superfície sensível. Um fotograma de um assunto do real, sem outros fotogramas a lhe darem sentido: um fotograma apenas, sem antes e sem depois. [KOSSOY, 1991, p28]

Esse registro congelado, domínio do tempo, isolado em seu aspecto residual do passado, surge como um inventário do tempo retratado. Nesse aspecto, uma coleção de fotos é uma proposição no campo do desejo da finalidade. O que se quer construir oscila entre o autor da foto e seu objeto. Nesse caso, um aspecto que não por acaso acaba ocorrendo é que a fotografia passa a ser um testemunho histórico, porém um testemunho do próprio autor.

No caso do AlmanaCh-AlbUm DE São CARlos 1916 - 1917, a presença da fotografia, entre os textos e os anúncios propagandísticos e da miscelânea literária, constitui uma inovação do gênero. A presença da foto em publicações de massa pode nos apontar para um caminho muito saudável: o 
da experiência da aura. Em Benjamin, a aura é definida como "uma peculiar fantasia de espaço e tempo: a aparição única de algo que está distante, por mais próximo que possa estar. Em uma tarde de verão, ficar contemplando uma cordilheira no horizonte, um ramo, que lancem a sua sombra sobre quem olha -isto significa respirar a aura desses montes, desse ramo". [BENJAMIM. 1989 p.228]. Sobre esse aspecto Benjamin notou que a fotografia significou uma experiência que é revestida de aura, de encanto e maravilha. Pois os sentidos de apoderamento da imagem explicitamente dados em jornais e em revistas ilustradas orientam-se por uma via que se afasta do real posto que não é a cópia em si, mas uma reprodução sob um dado olhar.

Nessa perspectiva, o ALMANACH-ALbUM DE SÃo CARLOS 1916 -1917 vai se utilizar da fotografia revelando panoramas de uma cidade icônica da modernidade local. Imagens urbanas e imagens rurais entremeiam as páginas dessa publicação. Deter-nos-emos, agora, a apreciar essas imagens e, assim, verificar a formulação de uma modernidade local e de uma educação dos sentidos que a perspectiva fotográfica pode aferir.

Por fim, uma explicação, ainda que não conclusa, pode nos fornecer algumas pistas interpretativas do fenômeno gerador da educação dos sentidos. O historiador Peter Gay pensa a cultura num processo de conformação de experiência descontínua e heterogênea, em que as visões de mundo vão se moldando de forma lenta entre indivíduos e grupos, em formas de pensar e de sentir que podem se contrapor ou complementar. O processo de formação da cultura não é resoluta, ao contrário, é um processo de formação constante e inacabado. Pensando em termos de modernidade, o sujeito desse processo passa a ser dotado não somente da racionalidade própria desse tempo das certezas, mas de uma sensibilidade expressa em termos de emoções, desejos, choques e tensões historicamente dadas.

É na modernidade que se forma uma educação dos sentidos. Se a técnica rouba a cena com suas demonstrações fantasmagóricas do campo material, não dando mais lugar ao original, ao ritual do objeto, tem-se aí o modo como os homens dos tempos modernos irão se comportar diante das inovações. Antes de nos determos em uma análise das imagens fotográficas do ALMANACH-ALBUM DE SÃo CARLOS 1916 - 1917, preferimos estabelecer as conexões entre o local e o global na esteira da experiência moderna.

\section{O LUGAR DA EXPERIÊNCIA NA EDUCAÇÃO DOS SENTIDOS}

O fenômeno urbano, ou o florescimento de cidades, que transformou vilarejos e aldeotas em concentrações consideráveis de gente e casas, vinha 
se acentuando no Brasil desde meados do Império. Diretamente, este fato está comprometido com a hegemonia alçada pela produção cafeeira e como corolário à intensa imigração da segunda metade do século XIX, iniciandose deste modo, o surgimento de cidades com perfil moderno, eivadas do espírito do progresso e da crença da civilização ${ }^{1}$

Era corrente no Brasil, especialmente no período republicano, a febre modernizadora. Essa onda se alastrou rapidamente, levando assim várias classes sociais a conviverem com esse processo dentro de experiências ambivalentes: desde as diversas classes de comerciantes até mesmo turbas de despossuídos dos grandes centros financeiros e políticos, como São Paulo e Rio de Janeiro.

Os resultados imediatos e materializados dessa riqueza, formada pela inserção do país nos quadros econômicos internacionais, forçou as elites urbanas a uma reinvenção do espaço urbano. Sob influência dos seus contatos cada vez mais amiudados com o mundo urbano e industrial europeu, embasbacavam-se com as transformações urbanas da capital do século $X I X$, a Paris reinventada do prefeito Haussmann.

Dessa forma, as cidades do interior paulista surgidas na esteira do café, revelam-se como objetos instigantes à compreensão dessa modernidade. As imbricações e ambigüidades de traços imprecisos e titubeantes dessa modernidade contêm, em seu interior, os choques de tensões entre razão/ desrazão, da civilização/barbárie, do arcaico/moderno, do urbano/rural, do atraso/progresso, do vencedor/vencido, do público/privado.

É nesse espaço de múltiplas nuances modernas, de simbologias e fantasmagorias que se forjou e se afirmou a República, portadora, como o recém-falecido regime monárquico, de uma vocação à ambivalência e ao ocultamento. ${ }^{2}$

Contudo, o agente dessa modernidade advinha de uma plutocracia do dinheiro, que vicejava seus lucros abrindo fazendas de café, algodão e cana, abrindo novas fronteiras do mítico Oeste Paulista em práticas de tocaias e grilagem de terras, apesar disso estava longe de ser um rude. Rei do café era letrado, de anel de doutor enfiado no anular, prendedor de gravata de esmeralda, colete, relógio de corrente, plastron, bengala e chapéu de côco.

Era delineadamente um empresário citadino, envolvido com as lides do café que se realizavam em muitas cidades, vivenciava cotidianamente a fremente vida bancária, das casas comissárias, do escritórios de despacho e, quando não menos provável, próximo aos bacharéis para articular seus gastos. Na política, não oferecia menos energia, pois, desta, adquiria espaço para afirmar seu prestígio nos empreendimentos. Dificilmente não era polilíngue, 
arriscava-se em trabalhos literários, era viajado e urbano. Ao fazer a viajem do deslocamento, ao frequentar lugares, Europa era o centro da cultura civilizacional, embebeda-se do espírito de modernidade e das pulsações ditadas pelo capitalismo. Esta paisagem material o levava e imaginar e a pretender para sua cidade os confortos da vida moderna, as belezas urbanas que ele vivera em Paris, Londres e Viena, que ele conhecera, naquele fin de siécle, como diria Machado, de vista e de chapéu.

Assim, ao procurar algum registro dessa experiência de contato entre mundos distantes, espacialmente mas tão conectados, as transformações econômicas da Belle Epoque, começo a desvendar a composição imagética do almanaCh-Album de São Carlos 1916 - 1917.

Nas trilhas do Almanach-Album

As páginas dessa publicação sobre o empenho de Francisco Camargo possuem um formato retangular e um acabamento muito interessante: ornamentações em estilo neoclássico e papel de excelente qualidade o que se vê na consulta que fizemos desse exemplar, recentemente, no Arquivo do Estado de São Paulo, ainda em bom estado perpassando já em quase 90 anos.

Procurarei privilegiar uma seqüência de imagens que mostrarão, evidentemente, o ambiente dessa cidade do interior paulista flagrado no momento em que é composto o almanach-album. Como leitor desse almanach e também com olhos de pesquisador, embora não estando no momento nem no local referidos, passo a utilizar do gesto do flaneur para poder expressar uma minha "andança" pela São Carlos do início do século XX.

Comecemos, então, nossa partida pelas páginas desta publicação.A primeira imagem selecionada, em meio a tantas sugestivas, foi a do prédio da Câmara Municipal. Ao focar a imagem, produz-se uma foto que captura a rua retilínea, a praça arborizada e higienizada, tendo ao fundo um automóvel estacionado. Trata-se de um flagrante que envolve tanto o discurso disciplinador proposto por Haussman, na Paris dos fins do oitocentos, ao mesmo tempo que mostra-se na imagem um boulevard que traz as impressões, matizes da ruralidade, aprisionadas em forma estética com o arranjo de árvores que fazem o adorno das ruas. Árvores na cidade eram um modo de trazer a natureza para perto, que o urbano havia engolido com seu jogo de arquiteturas de alvenaria e suas ruas pavimentadas. 


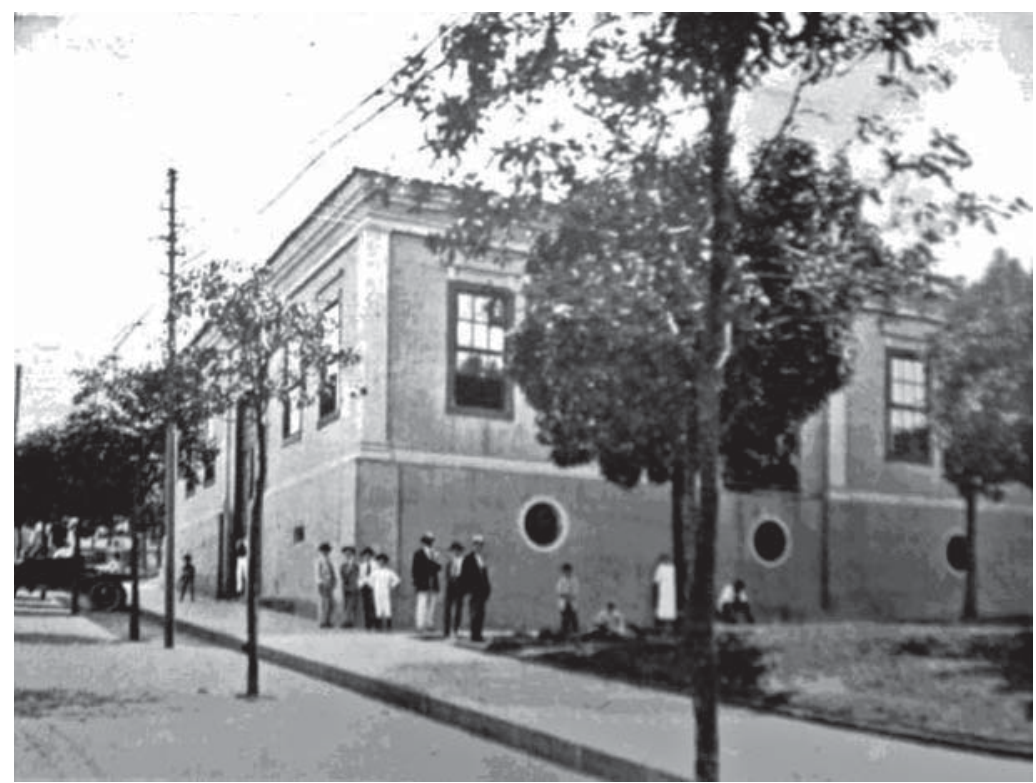

Câmara Municipal de São Carlos

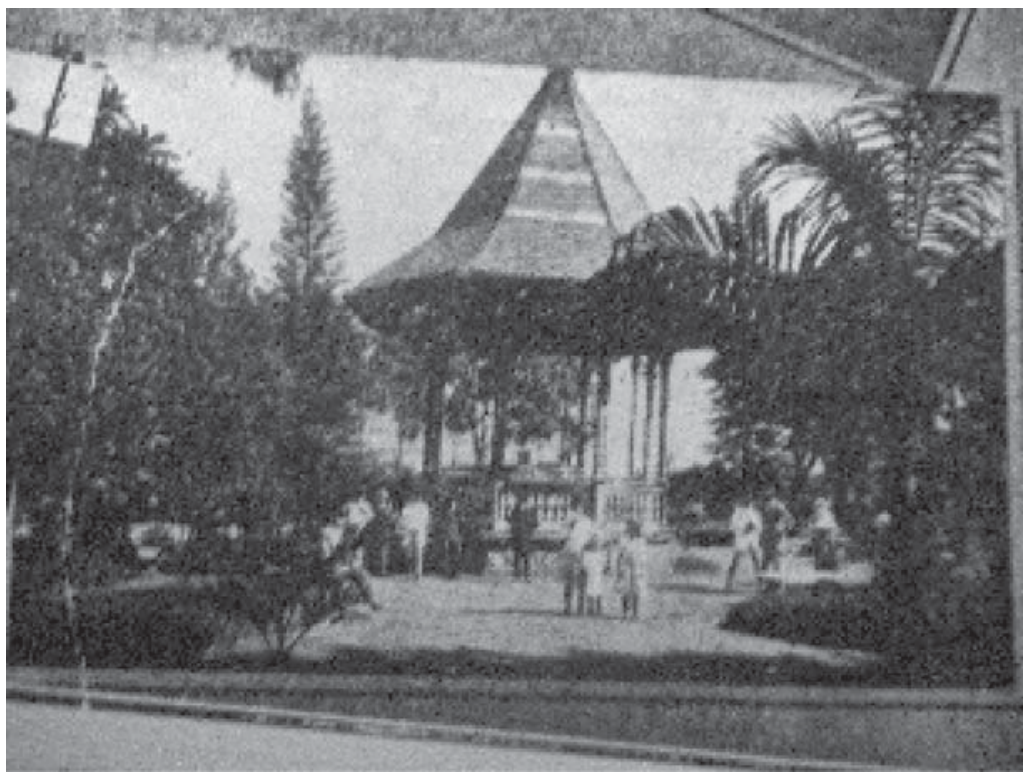

Quiosque, detalhe do Jardim Publico de São Carlos. In: Almanach-Album de São Carlos de 1916-1917. 
Já a segunda imagem, no folhear que faço do almanach-album, a percepção de que no conjunto das imagens compõe-se um caminho de percepções na educação dos sentidos do leitor visual que se preocupa em denotar o quadro de edifícios públicos, voltados para a configuração de um centro urbano provido de serviços essenciais, tais como o fórum, registro e certificação dos traços modernos, no conjunto de uma seqüência de fotos que configuram a existência de centros educativos, precursores da civilidade e da cultura. Pelos dados exibidos no almanach-album, São Carlos já possuía inúmeras escolas, dispostas na educação clássica ou abrigadas por gênero. Havia também ensino noturno e privado, que não fugia à regra das grades curriculares daquele tempo de orientação francesa. Em termos culturais, foi na inauguração da República que a educação ganhou destaque, posto que sua fundamentação básica fosse a de reorganizar a sociedade em novos parâmetros da sociedade emergente daqueles tempos. Em termos gerais, ocorre uma virtual luta de princípios filosóficos e concepções políticas advindas do positivismo, do darwinismo social e do liberalismo. Na prática, o positivismo realçou a confirmação de um ideal educacional ancorado num projeto, que buscava promover o conhecimento necessário à evolução dos indivíduos e, ao mesmo tempo, que se ampara na formação do ente "Nação" como formador de um espírito, de modelos pedagógicos, uma moral nos "novos cidadãos". Assim, as escolas são-carlenses, não fugindo a esse discurso formador, promovem a construção do cidadão moderno dentro da modernidade republicana.

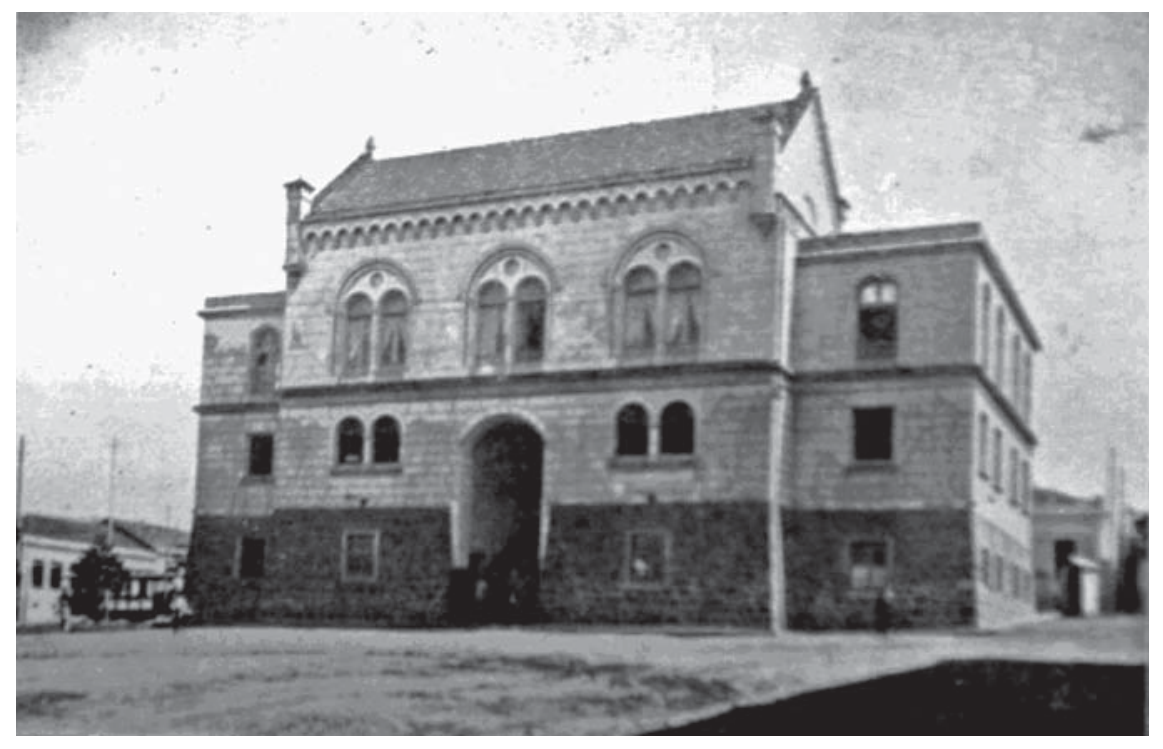

Fórum de São Carlos: in; Almanach-Album de São Carlos de 1916-1917. 


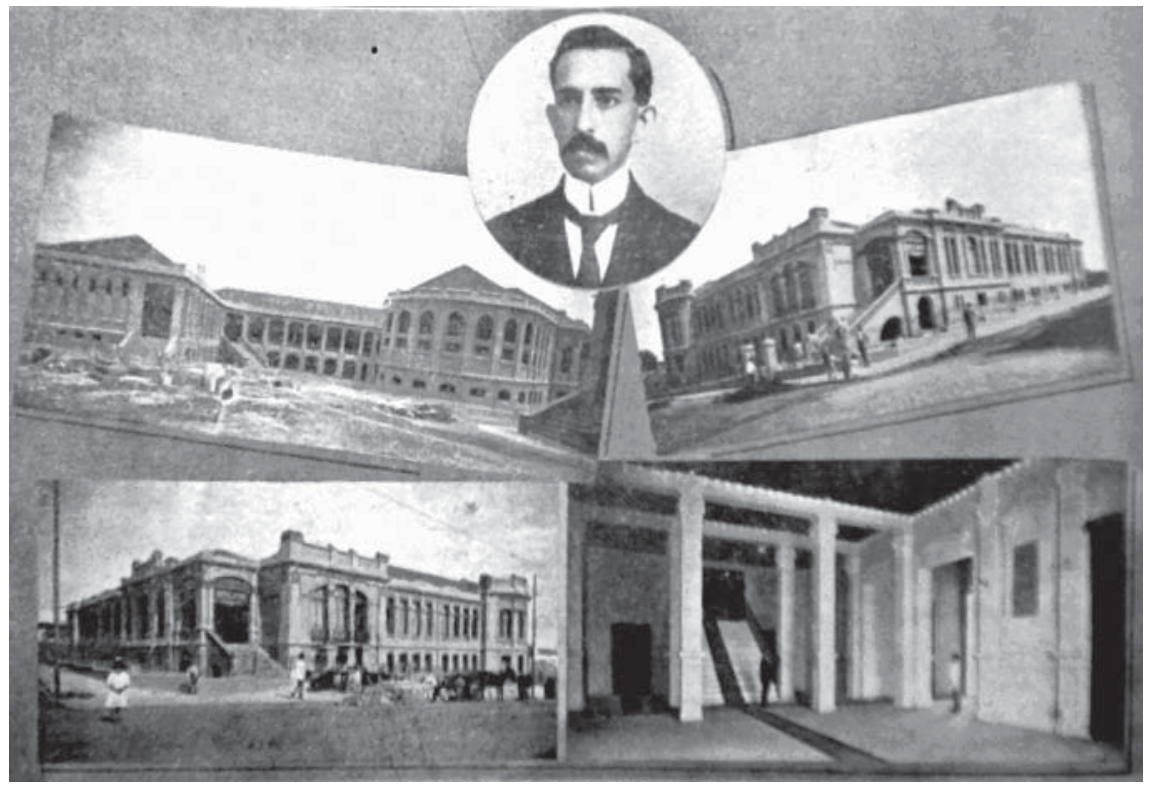

Escola Modelo de São Carlos

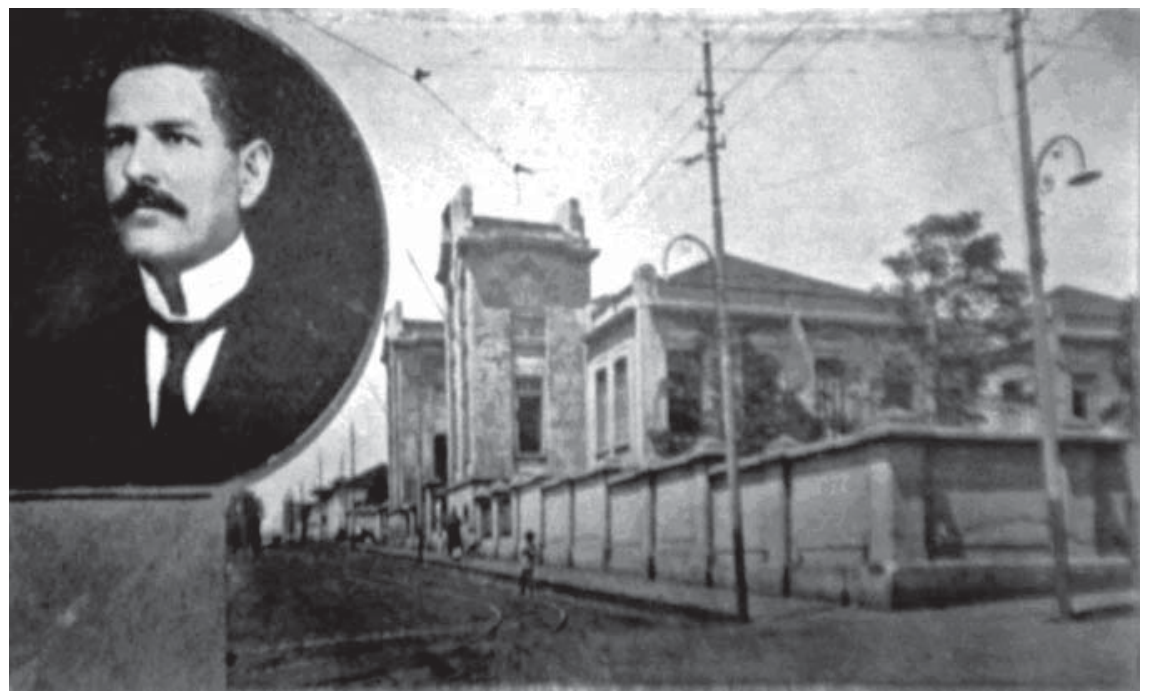

Escola Normal de São Carlos

História Revista, Goiânia, v. 14, n. 1, p. 129-148, jan./ jun. 2009 


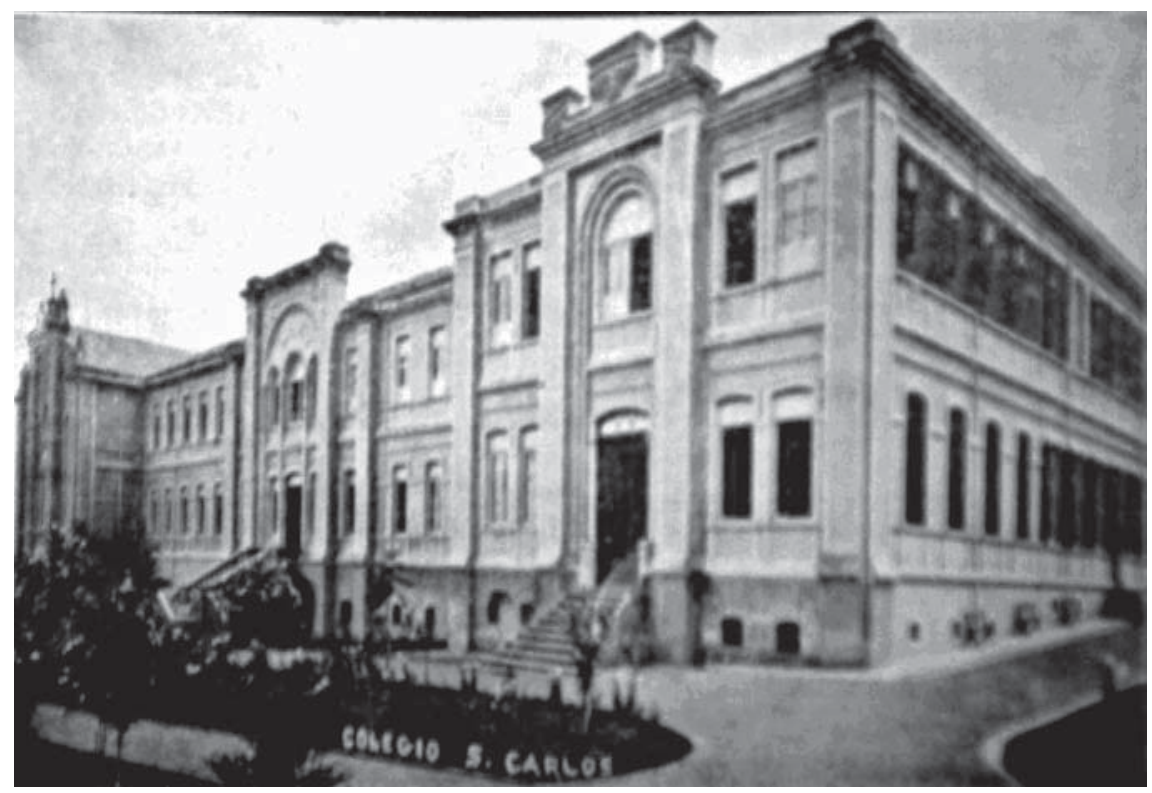

Colégio São Carlos

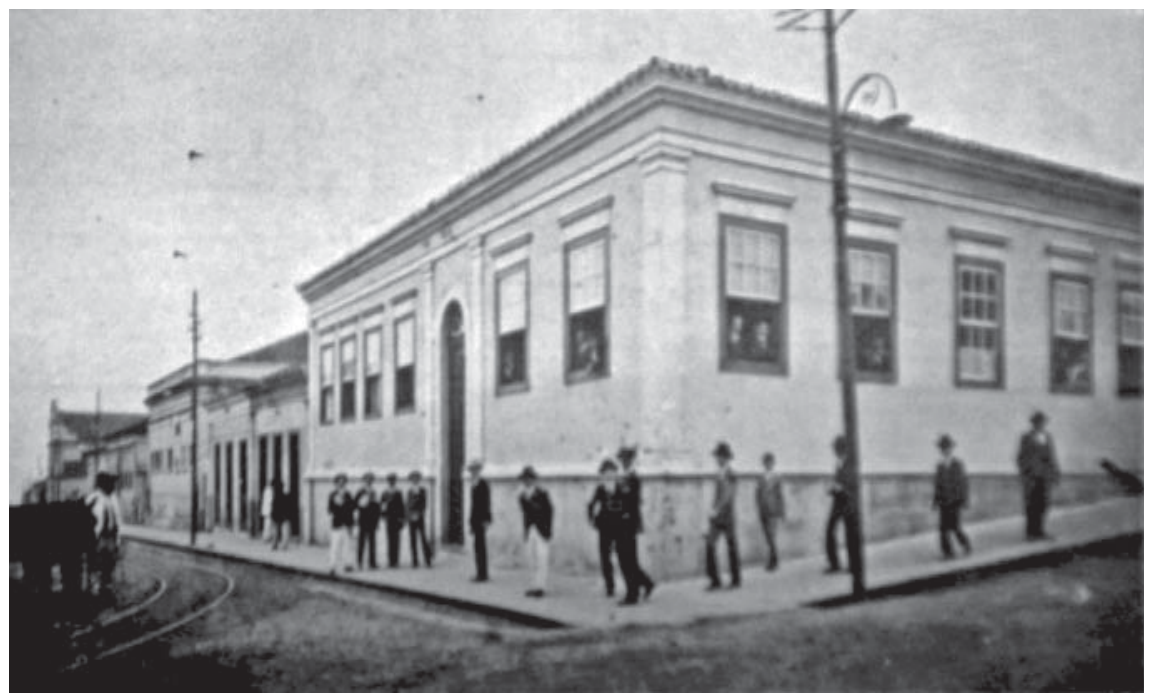

Atheneu Sãocarlense

J osé Evaldo de Mello Doin, Arrovani Luiz Fonceca, Humberto Perinelli Neto e Rafael Cardoso de Melo. A educação dos sentidos na leitura... 
A caminhada em forma de leitura agora paralisa-se um pouco para ver uma fantasmagoria. A existência dos bondes, marcantemente singrando o espaço urbano, já revela experiências modernas do hábito de sentir a cidade. Ela transfigura a cena urbana num choque em que a afirmação contínua da cidade como palco de um espetáculo moderno enuncia a certificação de uma modernidade em superação aos troles, tão comuns no início do século XX. Procurando, assim, mostrar-se senhor do território com seus maquinismos de velocidade e de afirmação do tempo, que fazem as pessoas se ocuparem agora dos horários determinados. Além de caracteres arquitetônicos e de equipamentos urbanos como a eletricidade, a racionalização da cidade se vai construindo através da existência dos primeiros bondes elétricos destacados na imagem e na Avenida São Carlos, principal artéria de circulação da cidade.

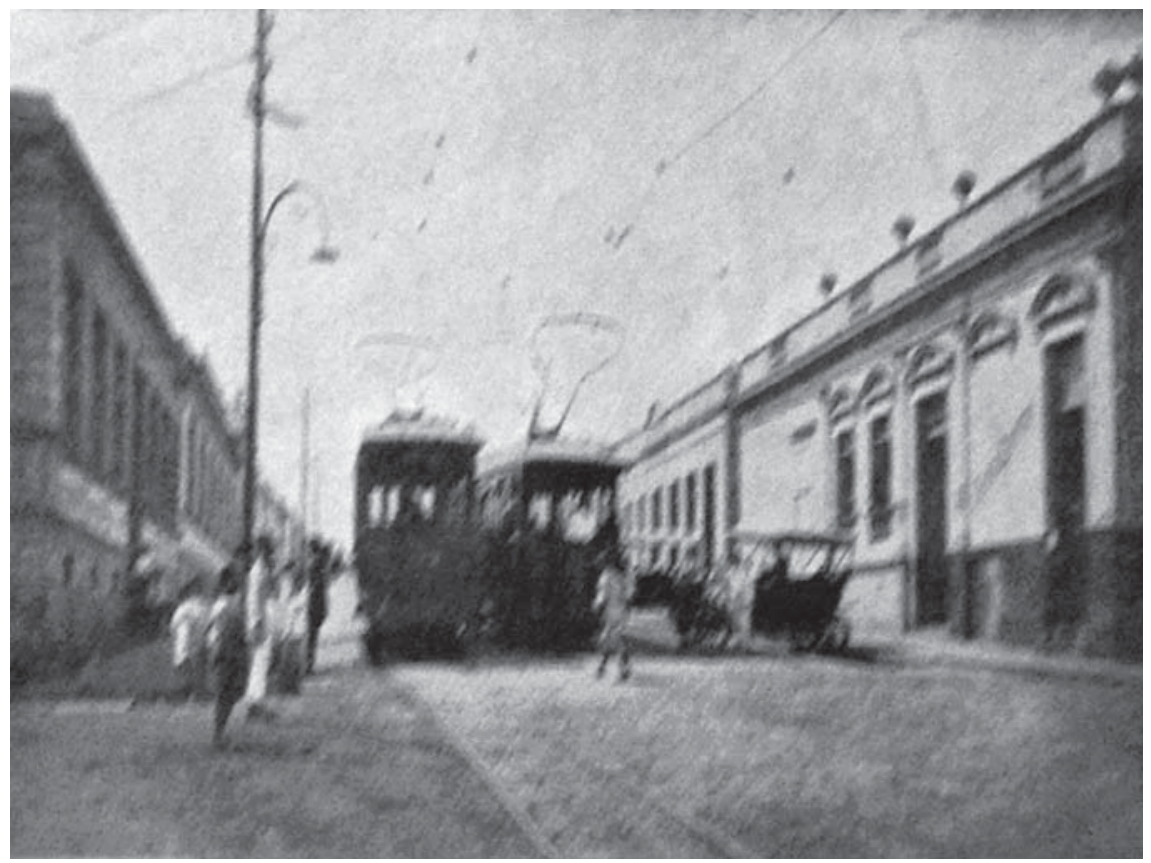

Avenida São Carlos e os bondes elétricos 


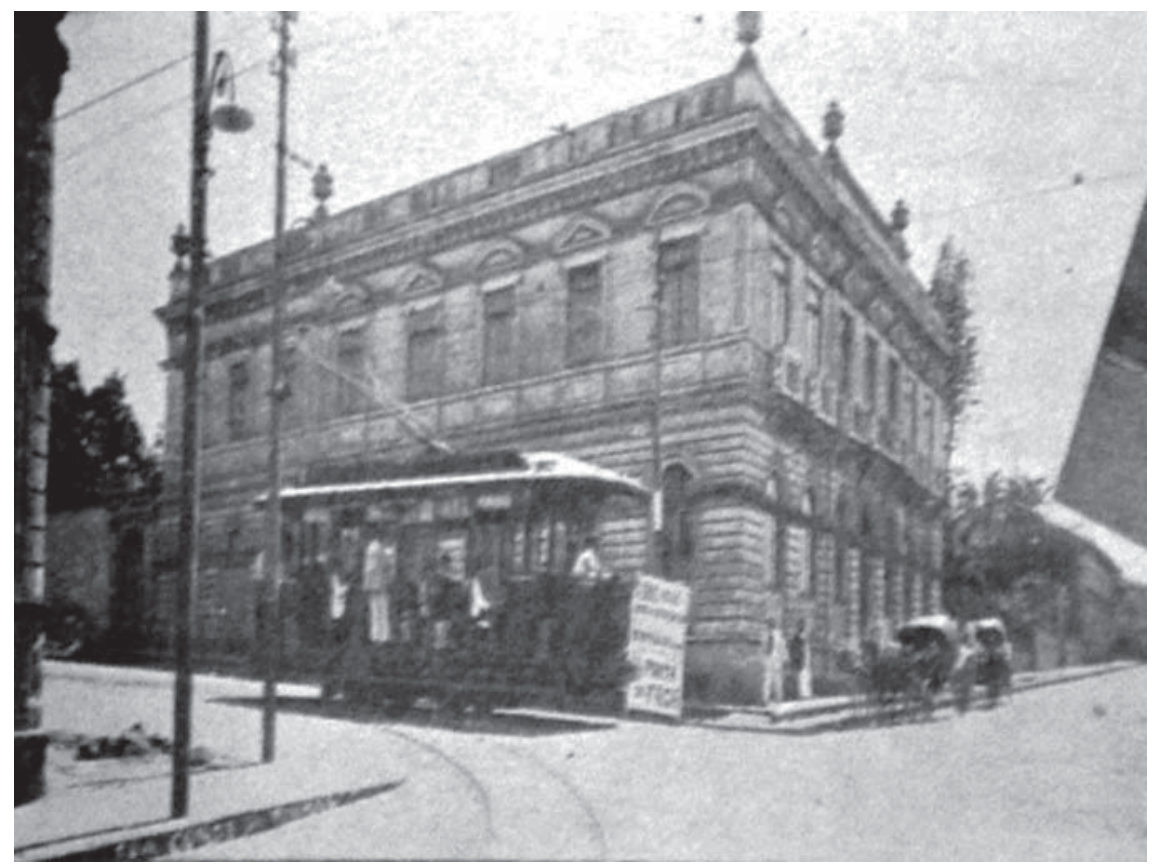

Avenida São Carlos nas imediações do jardim público

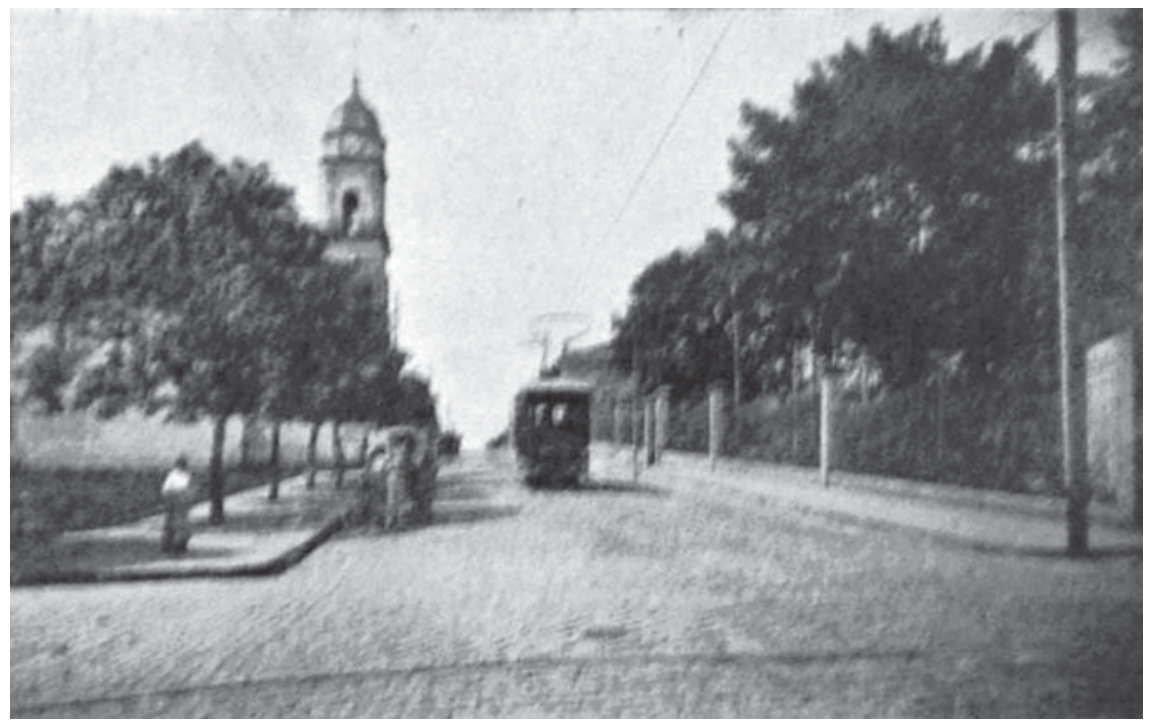

Avenida São Carlos

J osé Evaldo de Mello Doin, Arrovani Luiz Fonceca, Humberto Perinelli Neto e Rafael Cardoso de Melo. A educação dos sentidos na leitura... 
Editor do Almanach-Album de São Carlos, Francisco Camargo relata nas paginas iniciais a sensação de expectativa que em dezembro de 1914 ocorrera na cidade: a inauguração dos bondes elétricos.

[...] Estava prompta a linha da rua São Joaquim, que 19 daquelle mez, às 5 horas da tarde, era trafegada pelo primeiro bonde, que transitou desde a fábrica de tecidos até o depósito dos bondes, cheio de convidados, por entre as mais vivas e enthusiasticas acclamações do povo, que se agglomerava pelas esquinas afim de ve-lo passar.

Falhara, inteiramente a previsão sinistra! O bonde não saltava fora dos rails ao fazer as curvas: corria suavemente, deliciosamente, como os melhores e mais aperfeiçoados vehiculos da sua espécie.[...] A prefeitura mandou construir vistoso e artístico coreto naquelle logradouro publico, fez adornar com arcos de folhagens e com bandeirolas multicores as ruas Sete de Setembro, S. Carlos e Major José Ignácio, nos trechos a serem percorridos pelos bondes inaugurais, e, para maior ordem dos festejos, distribuiu convites a exmas famílias, sem os quais não era permitido o ingresso nos carros. As 14 horas, era belo de ver-se o aspecto do largo, onde se agglomerava uma multidão calculada em cerca de quatro mil pessoas [...]. [Almanach-Album de São Carlos, p.39-40]

Importante aspecto de festa, aglomeração, multidão que se avoluma para ver o "bulício" dos novos carros a que se entrecortarem a partir daquele momento a cidade, levando os operários, entre outros, ao translado das fábricas que já se evidenciam no município nas primeiras décadas do século XX.

Na São Carlos do Almanach, as fotos evidenciam a existência de uma aura. Aura que possibilita a visão do progresso, da civilização capitalista que, alterando as formas de contato com a cidade, denotam que os tempos da Belle Epoque cafeeira estão na cidade como se esta mesma fosse um museu do espetáculo imagético e efêmero da modernidade. Sons, ruídos, trânsito, circulação de veículos na área urbana, de pessoas, de notícias, de valores e padrões de comportamento. Esses objetos que saltam como um momento de espetacularização da modernidade, alteram as noções de espaço, tempo e velocidade. Estranhamento e conflito novos na relação com o lugar: o distante é rápido e o tempo não passa, corre. Pessoas nas ruas, entre conhecidos e desconhecidos.

Como diz Walter Benjamim: 
O mover-se através do tráfego implicava uma série de choques e colisões para cada indivíduo. Nos cruzamentos perigosos, inervações fazem-no estremecer em rápidas seqüências, como descargas de uma bateria. Baudelaire fala do homem que mergulha na multidão como em um tanque de energia elétrica. E, logo depois, descrevendo a experiência do choque, ele chama esse homem de um "caleidoscópio dotado de consciência". Se, em Poe, os passantes lançam olhares ainda aparentemente despropositados em todas as direções, os pedestres modernos são obrigados a fazê-lo para se orientar pelos sinais de trânsito. A técnica submeteu, assim, o sistema sensorial a um treinamento de natureza complexa. [Benjamim, 1988, p.124-125]

Contudo, algo surpreende enquanto se avança na leitura do AlmanachAlbum. As fotografias que recolhem da paisagem urbana uma das simbologias da sua modernidade, agora se estabelecem em imagens que capturam a fazenda, o cafeeiro, as máquinas de beneficiamento. O progresso que tem na urbanidade o seu lócus, tem na fotografia seu dissonante nesse passo. Se existe uma relação direta entre fotografia e urbanidade, que acaba agraciando a cidade como forma ícone. Aqui ela surge não como estímulos múltiplos da metrópole nem mesmo do cenário urbano da São Carlos bellepoquense, mas captura a paisagem rural em seu sentido capitalista e ressignifica no todo do almanaque como sendo uma das maravilhas auráticas do binômio cidade-campo.

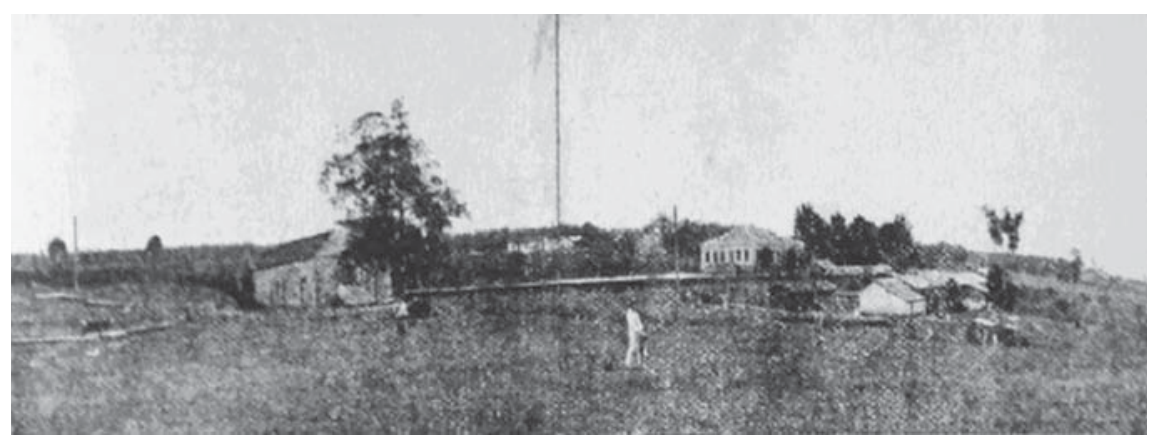

Fazenda Santa Barbara ${ }^{3}$ 


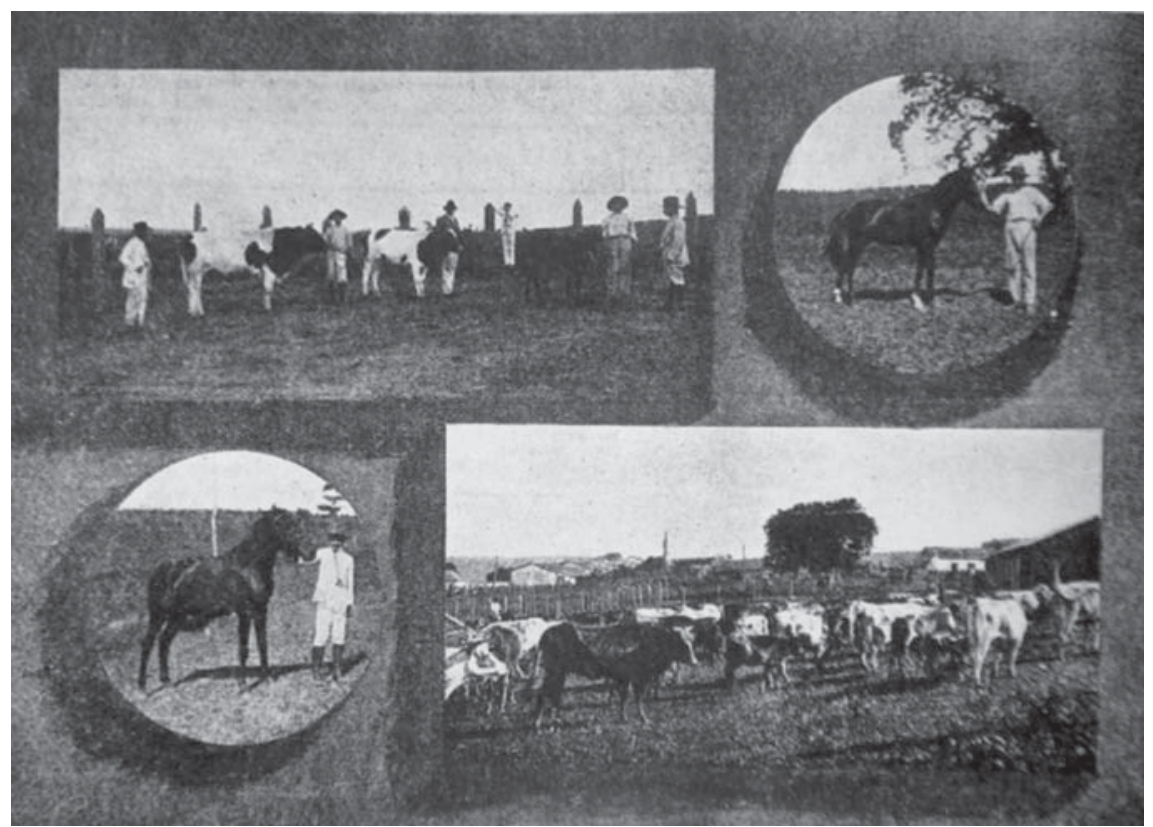

Fazenda Santa Barbara: criação de gado e cavalo

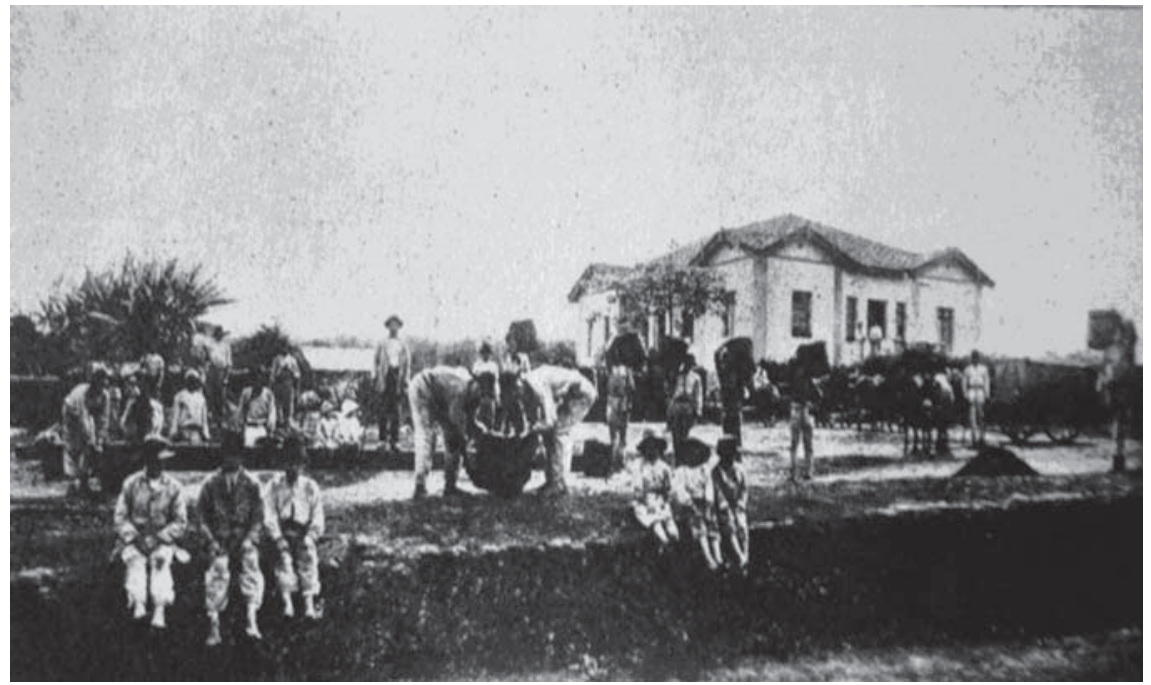

Fazenda São Pedro ${ }^{4}$

História Revista, Goiânia, v. 14, n. 1, p. 129-148, jan./ jun. 2009 


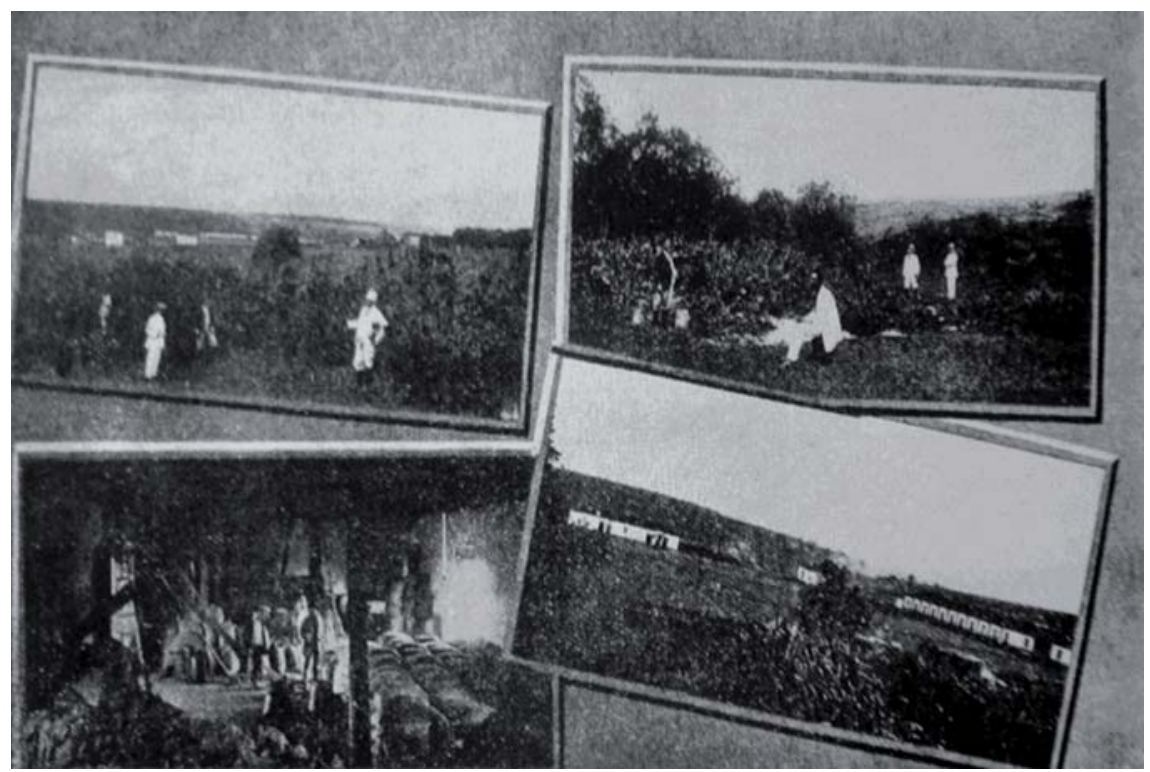

Fazenda Canchin ${ }^{5}$

Essa seqüência de imagens mostra o interesse em transformar o almanaque no carro-chefe das muitas benesses experienciadas pelo capitalismo cafeeiro. Uma relação, em principio oposta, parece mais uma vez complementar: seria o campo aponto da cidade ou vice-versa? Ao percebermos a fotografia no almanaque-Album de SÃo Carlos, podemos dizer que uma não existe sem o outro. O que desafia a nossa percepção, portando-nos de um olhar moderno e mais urbanóide, é o entrelaçamento ambivalente entre os espaços: de um lado, o bonde, o boulevar, rua retilínea, a eletricidade, a arquitetura; de outro, a paisagem rural flagrada nos animais que o cercam, na mão-de-obra nacional e estrangeira, o sequeiro de café no preparo de mais uma entressafra, o próprio pé de café, simbologia altiva. O próprio complexo cafeeiro, com toda a sua disposição e dinamismo, é o agente de todas as elucubrações urbanas. A centralidade do olhar fotográfico ALMANAQUE-ALBUM $D E$ SÃO CARLOS mira-se no maravilhamento do capital. Trata-se de um espetáculo que nos surpreende pela sua materialidade tanto urbana como rural. $\mathrm{O}$ imbricamento entre ambas faz-se presente e não existe uma sem a outra.

O Almanach-Album de São Carlos procura descrever, entre textos e imagens, a sensação moderna da cidade e da dinâmica fazenda capitalista, tendo como pano de fundo a materialização do capital cafeeiro com o seu 
arguto senso de apropriação do espaço urbano, principalmente entre o poder público, que se torna poroso em relação ao privado. A enunciação de sólidas imagens da cidade ilustradas nessa publicação a transforma numa cidade, mercantilizada e fortemente marcada por simbologias modernas. Nesse sentido, o almanaque passa a ser uma das narrativas que a cidade comporta, porém, com seus feixes de luz prismados, suas múltiplas narrativas, tornam-se reveladores de muitos caminhos que convergem por outro sentido na mesma cidade.

The education of the SenSes IN the ALMANACH-ALBUM DE $1916-1917$ OF SÃO CARLOS

Aвstract: The object, the almanac, has many uses and functions, and its intention here is related to the education of the individuals in their local modernity. The intention of this text is to explore the photographic reading universe that is shown in the São Carlos ALMANACH-ALBUM DE SÃO CARLOS 1916-1917, taking into account the "education of the senses", connecting the reader with the world progress dictations of the "Cafe Belle Epoque".

Key WoRDs: almanacs, modernity, education of sense, belle epoque cafe

\section{NOTAS}

1 CALDEIRA, Jorge. Mauá: empresário do Império. São Paulo: Companhia das Letras, 1995. Passim. Veja-se também a tese de doutorado de DOIN, José Evaldo de Mello. A divida externa no império: gênese do estado nacional e a modernização dos instrumentos de exploração - contribuição para o estudo da história econômica e financeira do Brasil - [1824-1864]. Tese [Tese de doutorado em História Econômica apresentada à FFLCH/USP] São Paulo: FFLCH/USP, 1986. P. 93 e segs.

2 "A ambivalência é, tanto quanto a coerção, uma característica reconhecida do poder. O poder domina os que o detêm e, por isso mesmo, estabelece uma dominação ilimitada sobre os súditos. Capacita a manipulação de forças, mas seu mau uso faz surgir a violência social e, com ela, a desordem. Situa-se aparentemente acima da sociedade e dos interesses particulares, mas permanece como organizador das desigualdades e das principais hierarquias, segundo as quais ordena-se essa sociedade. É, fator de unificação tanto quanto de competição e opressão, sendo parte de sua natureza a divisão e a violência legitimada. A proliferação simbólica - a "floresta de símbolos", segundo V. Turrner - mascara essa realidade aos súditos, até mesmo ao antropólogo que tem por função revelá-la e explicitá-la. A ambivalência visa 
apresentar o poder enquanto fenômeno natural e não um produto da história; só alcança em parte esse intento". BALANDIER, Georges. O contorno: poder e modernidade. Trad.: Suzana Martins. Rio de Janeiro: Ed. Bertrand Brasil, 1997. p. 97.

3 "banhada pelo Jacaré, em oposição topográfica de primeira ordem, a fazenda do snr. Cel. José Rodrigues Sampaio, muito digno presidente da Câmara Municipal de S. Carlos, embora não seja uma das maiores do município pela sua extensão e pelo numero de cafeeiros, é uma das melhores pela fertilidade do terreno e pelo esmero que é montada e tractada. [...] Toda a fazenda é illmuninada à luz electrica, fornecida pela Companhia Paulista de Eletricidade. [...] Tudo o que se vê em sua propriedade agrícola é bom, muito bom: sua residência, ainda que de construcção antiga, apresenta todo o conforto que se póde desejar; machinas da fazenda, aperfeioçoadíssimas, são movidas à electricidade; os terreiros, de 10.000 quadrados de superfície, são dos mais bellos e mais bem construídos; numerosas moradas de colonos. [...] o cel. J.R. Sampaio é um dos poucos que se dedicam carinhosamente à criação do Cavallo nacional, tão descuidosamente abandonado, e de que elle tem typos, que nada invejam os extrangeiros." In: Almanach-album de São Carlos, 1916-1917; s/p.

4 "Em terras planas, roxas e brancas, a 4 kilometros de São Carlos e a de 2 da Estaçao do Retiro, estende-se a fazenda de São Pedro, do snr Pedro de Souza Campos. Compreendendo 90 mil pés de café, dos quase 50 mil novos, a fazenda de São Pedro, corresponde aos cuidados incançáveis do seu zeloso proprietário, produzindo, em 10 annos, uma média de 7.500 arrobas." Idem, op. cit, s/p.

5 Uma das boas fazendas de São Carlos é por certo a do Canchim, propriedade do Exmo. Snr. Cel. Marcolino Lopes Barreto, deputado federal por este município, homem de uma actividade extraordinária.As terras da fazenda são muito boas, e estão divididas em duas porções: uma destinada a cultura do café - 350 mil pés - e outra constituída de vastas invernadas em que o Cel. Marcolino cria boa quantidade de optimos espécimens de gado vaccum e cavalar. Não é preciso alongar muito esta rápida noticia com pormenores sobre a fazenda do Canchim. As photographias que illustram este Álbum, mostram, que sobejo, o que é a fazenda, a sabia direcção que lhe é dada pelo seu proprietário, homem pratico e sagaz. Idem, op. cit, s/p.

\section{REFERÊNCIAS}

ALMANACH-ALBUM de São Carlos para o ano de 1916-1917. Franklin Castro. Organizador. Typographia Astistica. 1916-1917. 
BENJAMIN, Walter. Sobre alguns temas em Baudelaire. In: Obras Escolhidas, III, Charles Baudelaire, um lírico no auge do capitalismo. SP: Brasiliense, 1989, p.109.

BALANDIER, Georges. O contorno: poder e modernidade. Trad.: Suzana Martins. Rio de Janeiro: Ed. Bertrand Brasil, 1997

BERMAN, Marshall. Tudo que é sólido desmancha no ar - aventura da modernidade. São Paulo, Cia. das Letras, 1998.

BURKE, Peter. A cidade pré-industrial como centro de informação e comunicação. Estudos. Históricos, Rio de Janeiro, v. 8, n. 16, p. 194-198, 1995.

CALDEIRA, Jorge. Mauá: empresário do Império. São Paulo: Companhia das Letras, 1995.

DOIN, José Evaldo de Mello. A divida externa no império: gênese do estado nacional e a modernização dos instrumentos de exploração - contribuição para o estudo da história econômica e financeira do Brasil [1824-1864]. Tese de doutorado em História Econômica. São Paulo: FFLCH/USP, 1986

GAY, Peter. A experiência burguesa: da rainha Vitória a Freud: a educação dos sentidos. São Paulo. Cia das Letras. 2000.

GOMES, Ricardo Cordeiro. Todas as cidades, a cidade: literatura e experiência urbana. Rio de Janeiro: Rocco, 1994.

KOSSOY, Boris. Fotografia e História. São Paulo: Ateliê Editorial, 2003.

ROUANET, Sergio Paulo. A razão nômade. Walter Benjamin e outros viajantes. Rio de Janeiro: Editora da UFRJ, 1993. 